\title{
Patient-reported and Functional Outcomes of Bi-condylar Tibial Plateau Fractures Managed by Internal Screw Fixation in Combination with An Ilizarov Fixator: A Case Series of 22 Patients with Long-term Follow-up
}

Peter Larsen ${ }^{1}$, Jens Traerup ${ }^{2}$, Mindaugas Mikuzis ${ }^{3}$, Rasmus Elsoe ${ }^{4}$

\begin{abstract}
Introduction: The objective of this case series was to report the long-term patient-reported and functional outcomes of complex bicondylar tibial plateau fractures in patients treated with internal fixation in combination with an llizarov fixator.

Materials and methods: A retrospective series of cases. Patient-reported, radiological and functional outcomes were obtained with a mean of 9.4 years' follow-up.

Results: Twenty-two patients completed the follow-up. At follow-up, the mean age was 52.2 years, ranging from 26 to 69 years. The gender distribution was 14 males and 8 females. The mean knee injury and osteoarthritis outcome score (KOOS) was pain 72.5, symptoms 62.7, ADL 75.9, sport 35.4, and knee related quality of life (QOL) 56.4. Compared to a reference population, the present study reported worse outcome for the subscales: symptoms, sport, and QOL. The maximal isometric muscle strength for knee extension was $354 \mathrm{~N}$ for the noninjured leg and $325 \mathrm{~N}$ for the injured leg ( $p=0.27$ ). Assessment of gait functions showed a gait speed of $122.7 \mathrm{~cm} / \mathrm{second}$ and a cadence of 112.7 steps/minute. Gait speed and cadence showed no significant difference when compared to a reference population. Radiological examination of knee osteoarthritis (OA) showed 6 patients presented with none OA, 13 patients with mild OA, and 3 patients with severe OA.

Conclusion: Complex bicondylar tibial plateau fractures are associated with long-term decreased knee structure-specific patient-reported outcome (KOOS). In contrast, most patients presented with satisfactory long-term radiological and functional outcomes. More research is needed to understand the complex association between patient-reported outcomes and radiological and functional outcomes.

Level of evidence: IV. Series of cases.

Keywords: Complex bicondylar tibial plateau fractures: long-term follow-up, Functional outcomes, Internal fixation combined with external ring fixation, Patient-reported outcomes.

Strategies in Trauma and Limb Reconstruction (2019): 10.5005/jp-journals-10080-1432
\end{abstract}

\section{INTRODUCTION}

The incidence of tibial plateau fractures is 10.3/100,000/year, with the majority of complex bicondylar fractures secondary to highenergy trauma. ${ }^{1}$ A complex bicondylar fracture of the tibial plateau commonly involves fractures of the joint surfaces and the proximal metaphyseal area of the tibia combined with intraarticular soft tissue injuries. ${ }^{2,3}$

For decades, operative treatment of bicondylar tibial plateau fractures has been the treatment of choice. ${ }^{4}$ The operative treatment is challenging due to multifragmented bones in combination with cartilage damage and intraarticular soft tissue lesions. ${ }^{5}$ Several surgical procedures aiming to restore the joint surfaces obtain anatomic alignment of the bone, and rigid fixation has been studied in great depth. ${ }^{6-12}$ Surgical procedures often include open reduction and internal fixation, angle-stable locking plates, and/or the use of an external ring fixator with no clear advantage of any of the methods. ${ }^{6-11,13,14}$

The outcome after complex bicondylar fractures is reported with different degrees of functional disability, early exit from employment, and restrictions on QOL., ${ }^{4,9}, 15-20$ Development of posttraumatic $\mathrm{OA}$, early treatment with total knee replacement (TKR), and knee pain are commonly reported., 4,21-23

On average, patients presenting with a bicondylar complex tibial fracture are less than 50 years of age at the time of fracture. ${ }^{1}$
'Department of Occupational Therapy and Physiotherapy, Aalborg University Hospital, Aalborg, Denmark

${ }^{2-4}$ Department of Orthopedic Trauma Surgery, Aalborg University Hospital, Aalborg, Denmark

Corresponding Author: Rasmus Elsoe, Department of Orthopedic Trauma Surgery, Aalborg University Hospital, Aalborg, Denmark, Phone: +45 976600 00, e-mail: rae@rn.dk

How to cite this article: Larsen P, Traerup J, Mikuzis M, et al. Patientreported and Functional Outcomes of Bi-condylar Tibial Plateau Fractures Managed by Internal Screw Fixation in Combination with An Ilizarov Fixator: A Case Series of 22 Patients with Long-term Follow-up. Strategies Trauma Limb Reconstr 2019;14(2):85-91.

Source of support: Nil

Conflict of interest: None

Therefore, long-term follow-up studies, including patient-reported, radiological, and functional outcomes, are needed to understand the lifelong consequences of both facture types and differences in surgical treatment options.

The objective of this case series was to report the long-term patient-reported and functional outcomes of complex bicondylar tibial plateau fractures in all patients treated with internal fixation in combination with an external ring fixator. 


\section{Materials and Methods}

\section{Study Design and Recruitment of Patients}

The study design was a retrospective case series conducted at Aalborg University Hospital between 2005 and 2010, which included all patients with bicondylar tibial plateau fracture treated with internal fixation in combination with an external ring fixator.

Patients between 18 years and 100 years of age were eligible for inclusion. Only patients with complex bicondylar fractures including a metaphyseal extension of the tibia were included (AO-41C). ${ }^{24}$ Patients treated with angle stable plates, initial and secondary TKR, or internal fixation without the use of an external ring fixator were excluded. Patients not residing in the northern region of Denmark, patients with mental disability, and pregnant patients were also excluded.

All patients were contacted by mail and informed about the study, inviting them to participate. If patients did not reply, a phone call was placed to inform and invite them to participate.

The Danish Data Protection Agency (jrn: 2008-58-0028 ID 201790) approved the study. The Northern Denmark Committee for Science Ethics of (jrn: N-20170031) approved the study. The study followed the strengthening the reporting of observational studies in epidemiology statement. ${ }^{25}$

\section{Data Collection}

Chart reviews were used for retrospective data collection. Patients underwent clinical and radiological evaluations.

The primary outcome of the study was the knee injury outcome score (KOOS). ${ }^{26}$

\section{Surgical Treatment}

All fractures were managed with screw fixation. Both autogenous and allogenous bone grafts were used. The external fixator (Ilizarov) was fixed to the tibia by both hydroxyapatite-coated half-pins and olive-wires, per surgeon's choice. The alignment of the llizarov ring fixator was evaluated and corrected. Proximal fixation of the femur was used when necessary. Following discharge and frame removal, all patients received a standard individual physiotherapy program. Detailed overview of the surgical procedure is presented in Table 1 and Figure 1.

\section{Long-term Follow-up Procedure}

Baseline characteristics including the time of fracture, fracture classification, open or closed fracture (Gustilo classification), deep and/or pin infection, diabetes, and mode of injury were recorded from a retrospective review of medical charts.

\section{Patient-reported QOL}

The $\mathrm{KOOS}^{26}$ is a standardized patient-reported questionnaire developed to evaluate knee problems. Five subscales are included in the questionnaire: pain, ADL, symptoms, sport, and QOL. A score of 100 indicates no symptoms, and 0 indicates major symptoms. The KOOS reference data are available. ${ }^{27}$

The questionnaire Eq5D-5L evaluate general health outcome. ${ }^{28}$ The following five dimensions are included: mobility, usual activities, self-care, pain and discomfort, and anxiety or depression, and a self-rated $20-\mathrm{cm}$ scale with end points "the best health you can imagine" and "the worst health you can imagine". An Eq5d-5L index of 1 indicates full health and 0 indicates death. ${ }^{29}$ Eq5D reference data are available. ${ }^{30}$

\begin{tabular}{|c|c|c|c|c|}
\hline \multirow[b]{2}{*}{ ID } & \multicolumn{2}{|r|}{ Frame } & \multicolumn{2}{|c|}{ Screws } \\
\hline & Ilizarov & Femur fixation & $7.3 \mathrm{~mm}$ & $4.5 \mathrm{~mm}$ \\
\hline 1 & $x$ & & 3 & \\
\hline 2 & $x$ & & 3 & \\
\hline 3 & $x$ & & 4 & \\
\hline 4 & $x$ & & 2 & \\
\hline 5 & $x$ & & 2 & 1 \\
\hline 6 & $x$ & & 2 & \\
\hline 7 & $x$ & & 2 & \\
\hline 8 & $x$ & & 2 & 1 \\
\hline 9 & $\mathrm{x}$ & & & 1 \\
\hline 10 & $x$ & & 2 & \\
\hline 11 & $x$ & & 2 & \\
\hline 12 & $\mathrm{x}$ & & 2 & \\
\hline 13 & $x$ & & 2 & \\
\hline 14 & $x$ & & 1 & 1 \\
\hline 15 & $\mathrm{x}$ & & & 1 \\
\hline 16 & $x$ & & 2 & \\
\hline 17 & $x$ & & 2 & \\
\hline 18 & $x$ & & & 2 \\
\hline 19 & $x$ & & 2 & \\
\hline 20 & $x$ & & & 2 \\
\hline 21 & $x$ & & & 1 \\
\hline 22 & $x$ & & 2 & \\
\hline
\end{tabular}

\section{Radiological Outcomes}

At follow-up, lateral projections of the injured knee and standing anteroposterior X-rays were taken of both knees. Knee OA was classified as described by Kellgren and Lawrence. ${ }^{31}$ No radiological signs of OA were reported as "none", KL grades one and two were reported as "mild", and $\mathrm{KL}$ grades three and four were reported as "severe OA". At the time of follow-up, X-rays were evaluated for depression of the articular surface, alignment, and widening of the condyle. Depression of more than $5 \mathrm{~mm}$, widening of the condyle of more than $5 \mathrm{~mm}$, and malalignment of more than $3^{\circ}$ [mechanical medical proximal tibial angle (mMPTA) and anatomical posterior proximal tibial angle (aPPTA)] compared to the opposite side were considered significant.

\section{Muscle Strength}

Isometric muscle strength was measured by a dynamometer attached to the wall (Mecmesin). Tests of maximal knee flexion and knee extension for both legs were performed. The patients were asked to perform two tests of isometric maximal voluntary contraction for 3-4 seconds. The highest value was used for analysis. Between the tests, a pause of 30 seconds was observed.

\section{Gait Assessment}

The quality of gait and asymmetries were measured by walking on a pressure-sensitive mat (GAITRite System ${ }^{\oplus)}{ }^{32}$ The system registers spatial and temporal parameters of the gait cycle. Patients walked on a 6-m pressure-sensitive mat with a self-selected walking speed. Characteristics of the gait cycle were evaluated bilaterally with regard to stance time, swing time, single-support time, functional rotation, and step length. The percentage of asymmetry between 

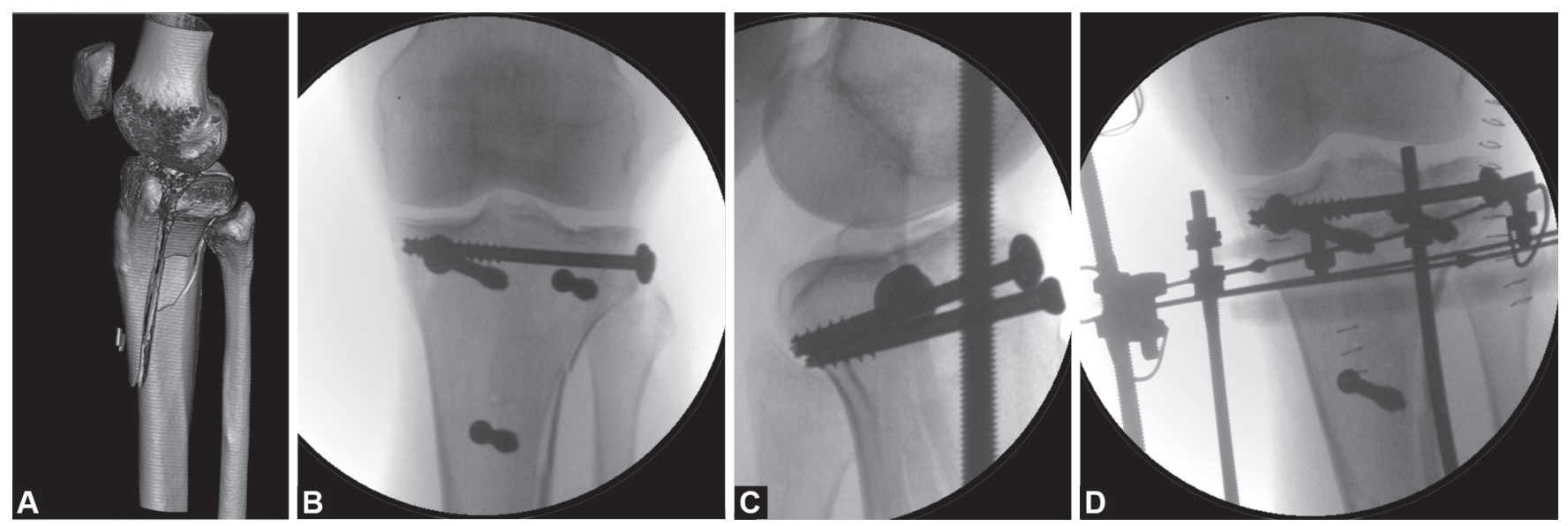

Figs $1 A$ to $D$ : Surgical procedure

the injured and the noninjured leg is given. ${ }^{33}$ Furthermore, coefficient of variance $(\mathrm{CV})$ of swing time was reported as a measure of variability in the gait cycle. Gait patterns were compared to a healthy reference population. ${ }^{34,35}$

\section{Statistics}

The QQ-plots were used to evaluate the distributions of variables for normality. Continuous data were expressed as mean and standard deviation (SD). Categorical data were expressed as frequencies.

The KOOS data, EQ5D index, and gait characteristics were compared to reference populations s, $^{270,34,35}$ using overlapping $95 \%$ confidence interval $(\mathrm{Cl})$.

To evaluate muscle strength between the injured and the noninjured leg and gait outcome, $t$ test was used. Gait asymmetry between the noninjured and injured legs was expressed as percentage asymmetry [100 $\times \ln$ (injured/noninjured)] for step length, single-support time, swing time, functional rotation, and stance time. The CV of stance time was calculated as $(100 \times \mathrm{SD} /$ mean).

The $\mathrm{KOOS}_{4}$ was calculated as recommended by Roos et al. ${ }^{36}$ for further analyzes. Pearson's correlations were used to express the association between $\mathrm{KOOS}_{4}$ and the relative difference in muscle strength, radiological outcome, and gait patterns.

A $p$ value of $<0.05$ was considered significant.

Statistical analyzes were performed using SPSS Statistics for Mac version 25.

\section{Results}

A total of 52 patients were treated for a complex bicondylar tibial plateau fracture (AO 41-C) with internal screw fixation in combination with external ring fixation during the study period. At the time of follow-up, it was reported that 3 patients were dead, 12 patients met one of the exclusion criteria, and 15 patients declined to participate.

A total of 22 patients were eligible for participation. Mean age at follow-up was 52.2 years, ranging from 26 to 69 years. Eight patients were female, and 14 were male. The mean time of follow-up was 9.4 years, ranging from 7 to 12 years. Table 2 presents the baseline characteristics of all patients.

\section{Patient-reported Outcomes}

The mean KOOS subscale scores were pain $72.5(\mathrm{Cl} 63.1$ to 81.9$)$, symptoms 62.7 (Cl 54.5 to 70.9$), A D L 75.9(\mathrm{Cl} 67.1$ to 84.6), sport
Table 2: Baseline characteristics

\begin{tabular}{|c|c|}
\hline Baseline characteristics of the 22 patients & \\
\hline Age at follow-up, mean (range) & $52.2(26-69)$ \\
\hline Follow-up length in years, mean (range) & $9.4(7-12)$ \\
\hline Time in frame in months, mean (range) & $4.6(2-13)$ \\
\hline \multicolumn{2}{|l|}{ Sex, $n$} \\
\hline Male & 14 \\
\hline Female & 8 \\
\hline BMI, mean (SD) & $28.3(5.2)$ \\
\hline \multicolumn{2}{|l|}{ Energy, $n$} \\
\hline High & 10 \\
\hline Low & 12 \\
\hline \multicolumn{2}{|l|}{ Fracture classification, $n$} \\
\hline OTA-41-C1 & 4 \\
\hline OTA-41-C2 & 2 \\
\hline OTA-41-C3 & 16 \\
\hline \multicolumn{2}{|l|}{ Open fractures (Gustilo), $n$} \\
\hline I & 1 \\
\hline ॥ & 1 \\
\hline III & 1 \\
\hline \multicolumn{2}{|l|}{ Infection, $n$} \\
\hline Deep infection & 0 \\
\hline Superficial or pin infection & 5 \\
\hline \multicolumn{2}{|l|}{ Secondary surgical treatment, $n$} \\
\hline Removal of screws & 8 \\
\hline Knee arthroscopy & 2 \\
\hline \multicolumn{2}{|l|}{ Smoking habits, $n$} \\
\hline Never & 7 \\
\hline Previous & 15 \\
\hline Present & 4 \\
\hline \multicolumn{2}{|l|}{ Diabetic, $n$} \\
\hline Yes & 3 \\
\hline No & 19 \\
\hline Other fractures, $n$ & 5 \\
\hline Crus & 1 (injured side) \\
\hline Calcaneus & 1 (injured side) \\
\hline Digiti pedis & 1 (injured side) \\
\hline Femur & 2 (noninjured side) \\
\hline
\end{tabular}

$n=$ number; $\mathrm{SD}=$ standard deviation 
Table 3: Patient reported outcomes compared to reference populations

\begin{tabular}{|c|c|c|c|c|c|}
\hline & \multicolumn{5}{|c|}{ KOOS } \\
\hline & Pain & Symptoms & $A D L$ & Sport & $Q O L$ \\
\hline \multicolumn{6}{|c|}{ Study population } \\
\hline Mean & 72.5 & 62.7 & 75.9 & 35.4 & 56.4 \\
\hline $95 \% \mathrm{Cl}$ & $63.1-81.9$ & $54.5-70.9^{*}$ & $67.1-84.6$ & $23.0-47.7^{*}$ & $45.2-67.6^{*}$ \\
\hline \multicolumn{6}{|c|}{ Reference population } \\
\hline \multirow[t]{3}{*}{$95 \% \mathrm{Cl}$} & $86.7-88.2$ & $85.4-86.9$ & $86.5-88.1$ & $72.5-75.1$ & 77.4-79.6 \\
\hline & \multicolumn{5}{|c|}{$E Q 5 D-5 L$} \\
\hline & Index & & VAS & & \\
\hline \multicolumn{6}{|c|}{ Study population } \\
\hline Mean & 0.752 & & 73.4 & & \\
\hline $95 \% \mathrm{Cl}$ & $0.673-0.831^{*}$ & & $65.3-81.5$ & & \\
\hline \multicolumn{6}{|c|}{ Reference population (male/female) } \\
\hline $95 \% \mathrm{Cl}$ & $0.880-0.896 /$ & & & & \\
\hline
\end{tabular}

$\mathrm{Cl}$, confidence interval

*Significant difference

Table 4: Radiological outcome

\begin{tabular}{lc}
\hline Radiological outcome postoperatively & $n$ \\
\hline Malalignment $>3^{\circ}$ & 4 \\
Condylar widening $>5 \mathrm{~mm}$ & 2 \\
Depression $>5 \mathrm{~mm}$ & 7 \\
Number of affected patients & 7 \\
Radiological outcome at follow-up & \\
Malalignment $>3^{\circ}$ & 4 \\
Condylar widening $>5 \mathrm{~mm}$ & 5 \\
Depression $>5 \mathrm{~mm}$ & 8 \\
Number of affected patients & 10
\end{tabular}

At follow-up, the radiological assessments were made on AP and lateral X-rays. $n=$ number. Depression of more than $5 \mathrm{~mm}$, condylar widening of more than $5 \mathrm{~mm}$, malalignment of more than $3^{\circ}$ (MPTA, PPTA) compared to the opposite site were considered significant

35.4 (Cl 23.0 to 47.7), and QOL 56.4 (Cl 45.2 to 67.6). Compared to the reference population, ${ }^{27}$ the study population reported nonoverlapping $95 \% \mathrm{Cl}$ for the subscales: symptoms, sport, and QOL, implying worse outcome (Table 3).

The mean Eq5D-5L index score was $0.752,(\mathrm{Cl} 0.6783$ to 0.831). The mean age of the study population were compared to the corresponding 10 years' incremental age-group of the Danish reference population. ${ }^{30}$ The study population reported nonoverlapping $95 \% \mathrm{Cl}$, implying worse outcome (Table 3 ).

\section{Radiological Outcomes}

At follow-up, X-rays showed 10 patients presented with malalignment, condylar widening $>5 \mathrm{~mm}$, and/or articular depression $>5 \mathrm{~mm}$. Following initial surgery and subsequent postoperative adjustment of the frame, seven patients presented with widening of the condyles $>5 \mathrm{~mm}$, malalignment, and/or articular depression $>5 \mathrm{~mm}$ (Table 4).

At the time of follow-up, the radiological outcome of knee $O A$ in the injured knee showed 6 patients presented with none OA, 13 patients with mild $O A$, and 3 patients with severe $O A$. In the uninjured knee, 15 patients presented with none OA and 7 patients presented with mild OA.
Nonsignificant and weak correlations were found between the presence of malalignment $>3^{\circ}$, condylar widening $>5 \mathrm{~mm}$ or articular depression $>5 \mathrm{~mm}$, and $\mathrm{KOOS}_{4}$ scores $(R=0.22, p=0.32)$.

\section{Outcome for Muscle Strength}

The assessment of maximal isometric muscle strength for knee flexion was $232 \mathrm{~N}$ (SD 90.3) for the noninjured leg and $211 \mathrm{~N}$ (SD 99.3) for the injured leg $(p=0.58)$. The assessment of maximal isometric muscle strength for knee extension was $354 \mathrm{~N}$ (SD 132.7) for the noninjured leg and 325N (SD 158.7) for the injured leg ( $p=0.27)$.

Weak and nonsignificant correlations were found between the relative difference in muscle strength and $\mathrm{KOOS}_{4}$ scores (knee extension: $R=0.09, p=0.71$, knee flexion: $R=0.17, p=0.44$ ).

\section{Outcomes for Gait Assessments}

The mean gait speed was $122.7 \mathrm{~cm} /$ second ( $\mathrm{Cl} 109.5$ to 135.9). The mean cadence was 112.7 steps/minute ( $\mathrm{Cl} 107.3$ to 118.1). The study population report nonoverlapping $95 \% \mathrm{Cl}$ between both gait speed and cadence compared to the reference population of normal gait parameters by Oberg et al., ${ }^{34}$ implying that no difference was observed in these gait patterns.

Weak and nonsignificant correlations were found between gait speed and cadence and $\mathrm{KOOS}_{4}$ scores (speed: $R=0.42, p=0.05$, cadence: $R=0.39, p=0.08$ ).

Table 5 presents gait characteristics of the injured and the noninjured leg including calculations of asymmetry in gait patterns. The asymmetry in single support was $4.1 \%$ and in step length $3.2 \%$. The asymmetry of variability in the swing phase presented as the coefficient of variation was $6.7 \%$.

Nonsignificant and weak correlations were found between asymmetry in gait patterns and $\mathrm{KOOS}_{4}$ scores (swing time: $R=$ $0.28, p=0.2$, single support $R=-0.28, p=0.2$, and step length $R=0.09, p=0.69$ ).

\section{Discussion}

This case series reported the long-term patient-reported, functional, and radiological outcomes in patients following complex bicondylar tibial plateau fractures, who were all treated with internal fixation in combination with an Ilizarov fixator. At a mean of 9.4 years, 


\begin{tabular}{|c|c|c|c|}
\hline Gait outcomes of asymmetry & Mean (\%) & $S D$ & $p$ \\
\hline Single support injured (seconds) & 0.41 & 0.04 & 0.16 \\
\hline Single support noninjured & 0.41 & 0.04 & \\
\hline Single support asymmetry (\%) & 4.1 & 3.0 & \\
\hline Step length injured (cm) & 64.6 & 11.3 & 0.44 \\
\hline Step length noninjured & 64.6 & 11.2 & \\
\hline Step length asymmetry (\%) & 3.2 & 2.7 & \\
\hline Swing time injured (sec) & 0.42 & 0.04 & 0.10 \\
\hline Swing time non-injured & 0.41 & 0.03 & \\
\hline Swing time asymmetry (\%) & 4.1 & 3.1 & \\
\hline Stance time injured (seconds) & 0.66 & 0.11 & 0.18 \\
\hline Stance time noninjured & 0.66 & 0.12 & \\
\hline Stance time asymmetry (\%) & 2.0 & 1.4 & \\
\hline Rotational foot injured $\left({ }^{\circ}\right)$ & 6.7 & 5.5 & 0.43 \\
\hline Rotational foot noninjured & 7.0 & 5.2 & \\
\hline Rotational foot asymmetry (\%) & 13.3 & 99.2 & \\
\hline Variance of swing time injured (CV) & 3.6 & 2.1 & \\
\hline Variance of swing time noninjured & 3.2 & 2.7 & \\
\hline $\begin{array}{l}\text { Variance of swing time asymmetry } \\
(\%)\end{array}$ & 6.7 & 92.4 & \\
\hline
\end{tabular}

$\mathrm{SD}$, standard deviation

follow-up patient-reported outcome score was worse compared to a reference population.

Extensive research has already been performed investigating the functional and radiological outcomes of surgically treated bicondylar tibial plateau fractures. However, most studies included mixed fracture types, different surgical treatment modalities, and did not include patient-reported outcomes on long-term follow-up. The present study reported the long-term knee injury-specific KOOS score and showed worse outcome for the subscale symptoms, sport, and QOL. The generic health related quality of life (HRQOL) score and Eq5D-5L index showed worse outcome compared to a national age-matched reference population. The residual deficit in long-term patient-reported outcomes following bicondylar tibial plateau fractures is comparable to the studies by Ahearn et al. ${ }^{11}$ (40.5 months' follow-up) and Jansen et al. ${ }^{12}$ (67 months) in patients treated with open reduction internal fixation (ORIF), locking plates or screws, or external fixation or in combination. Regardless of the treatment modalities, impairments in patient-reported outcomes are common and may be explained by the severe nature of intraarticular bicondylar fractures including multifragmented joint bearing parts of the tibia in combination with injury to the cartilage and intraarticular soft tissue structures. ${ }^{11}$

Although worse long-term structure-specific (KOOS) and generic HRQOL were observed in the present study, most patients included presented with satisfactory long-term radiological and functional outcomes. Several studies report satisfactory functional and radiological outcomes, regardless of the surgical method used. ${ }^{11,12,37}$ However, these satisfactory radiological and functional results do not seem to correlate to equally satisfactory patientreported outcome. ${ }^{11}$

A high risk of early-onset of posttraumatic OA following tibial plateau fractures is well established. ${ }^{4,9,12,22}$ The present study showed 6 patients with no OA, 13 patients with mild OA, and 3 patients with severe $O A$ in the injured knee at 9.4 years' follow-up. In the noninjured knee, seven patients presented with mild OA, which might indicate an increased risk of developing posttraumatic OA in the injured knee, compared to the noninjured following a tibial plateau fracture. These results are comparable to other studies reporting on the development of posttraumatic OA following bicondylar tibial plateau fractures. Regardless of surgical treatment modality, the incidence of knee OA has been reported with a wide range between $17 \%$ and $83 \%$ and with an increasing incidence with age at the time of fracture and loss of reduction. ${ }^{4,8,12,38,39}$ The present study excluded patients treated with TKR before follow-up. This information is highly important when interpreting the outcome of posttraumatic OA in the present case series, as some patients with severe OA have likely been excluded.

Little is known regarding muscle strength and gait function at long-term following complex bicondylar tibial plateau fracture. Results from the present study showed a decrease in knee extension (8\%) and knee flexion strength (9\%) at the injured leg compared to the noninjured leg. However, no significant difference between muscle strength for knee extension and knee flexion was found between injured and noninjured leg. This is in contrast to Honkonen et al. ${ }^{40}$ reporting significant $15 \%$ weaker quadriceps strength in the injured limb compared to the uninjured limb at 3 to 13 years' follow-up following a tibial plateau fracture. Moreover, this is supported by Gaston et al. ${ }^{41}$ reporting significant impairment in knee extension and knee flexion strength and that the majority of patients have not fully recovered 1 year after a tibial plateau fracture. These differences may be explained by the longer follow-up of 9.4 years in the present study. This notion is supported by Honkonen et al., ${ }^{40}$ reporting that difference in muscle strength tends to diminish with longer follow-up time. Furthermore, differences in fracture pattern and mode of injury might play an important part, as both Honkonen et al. ${ }^{40}$ and Gaston et al. ${ }^{41}$ reported on population with both single-column plateau fractures and bicondylar fractures, which were treated by a variety of different surgical methods.

Short-term asymmetry in gait patterns is commonly reported in bicondylar tibial plateau fractures. ${ }^{17}$ However, most studies reporting the functional outcome after tibial plateau fractures lack objective measurements of gait function. Results from this study indicated that patients obtained almost normal gait. This is in contrast to Warschawski et al. ${ }^{15}$ reporting $18 \%$ slower velocity and $8 \%$ slower cadence in patients 3.2 years following bicondylar tibial plateau fractures. Moreover, Warschawski et al. ${ }^{15}$ examined the difference in step length and single-limb support compared to a matched reference population and reported significant deviations in patients following a bicondylar tibial plateau fracture. The present study reported gait asymmetries in step length of 3.1\% and single support of $4.1 \%$ between injured and noninjured leg. Compared with the data on step length from healthy individuals reported by Patterson et al., ${ }^{35}$ these findings indicated almost symmetrical gait patterns in patients from this case series, as 3\% asymmetry in step length for healthy individuals is reported. The difference in findings between studies may be explained by the differences in follow-up time and surgical procedures, lack of radiological results, and missing data of knee OA. However, all studies included relatively small samples, and more research is needed.

The present study showed nonsignificant and weak correlations between $\mathrm{KOOS}_{4}$ and the presence of malalignment $>3^{\circ}$, articular depression $>5 \mathrm{~mm}$ and/or widening of the condyle $>5 \mathrm{~mm}$. Moreover, nonsignificant and weak correlations were found between gait outcomes and $\mathrm{KOOS}_{4}$ and between relative difference in muscle strength and $\mathrm{KOOS}_{4}$. These explorative findings should be interpreted with care due to low rate of participation and large 
variance in all outcome measurements. As a consequence, largescale studies are needed to answer these important questions regarding clinical interpretations.

To the authors' knowledge, this is the first study to report the patient-reported, radiological, and functional long-term outcomes of complex tibial plateau fractures, who were all treated with internal fixation in combination with a ring fixator. Several limitations may be addressed. First, the observational design of the study implied that conclusion regarding causality cannot be drawn. Moreover, this case series included only 22 patients that may imply a selection bias due to the rate of participation. However, complex bicondylar fractures are rare, and long-term reports on patients are missing. Moreover, patients treated with TKR have been excluded which might have influenced the outcome as patients with severe OA symptoms are presumed to have worse functional outcomes. Despite limitations, the authors believe that this long-term report provides useful information on complex bicondylar tibial plateau fractures treated with internal fixation in combination with an external ring fixator.

\section{Conclusion}

In all patients treated with internal fixation in combination with an llizarov fixator following a complex bicondylar tibial plateau fracture, long-term decreased knee structure-specific patientreported outcome (KOOS) was observed. In contrast most patients presented with satisfactory long-term radiological and functional outcomes. More research is needed to understand the complex association between patient-reported outcomes and radiological and functional outcomes.

\section{Ethical Standards}

All procedures performed in the study were in accordance with the ethical standards of the regional national research committee and with the 1964 Helsinki declaration and its later amendments or comparable ethical standards.

\section{ACKNOWLeDgments}

The Department of Orthopaedic Surgery and the Department of Occupational and Physiotherapy, Aalborg University Hospital, Denmark, is acknowledged for proving unrestricted grants.

\section{References}

1. Elsoe R, Larsen $P$, Nielsen NPH, et al. Population-based epidemiology of tibial plateau fractures. Orthopedics 2015;38(9):e780-e786. DOI: 10.3928/01477447-20150902-55.

2. Albuquerque RP, Hara R, Prado J, et al. Epidemiological study on tibial plateau fractures at a level I trauma center. Acta Ortop Bras 2013;21(2):109-115. DOI: 10.1590/S1413-78522013000200008.

3. Gardner MJ, Yacoubian S, Geller D, et al. The incidence of soft tissue injury in operative tibial plateau fractures: a magnetic resonance imaging analysis of 103 patients. J Orthop Trauma 2005;19(2):79-84. DOI: 10.1097/00005131-200502000-00002.

4. Rademakers MV, Kerkhoffs GM, Sierevelt IN, et al. Operative treatment of 109 tibial plateau fractures: five- to 27-year follow-up results. J Orthop Trauma 2007;21(1):5-10. DOI: 10.1097/BOT.0b013e31802c5b51.

5. Joveniaux $\mathrm{P}, \mathrm{Ohl} \mathrm{X}$, Harisboure $\mathrm{A}$, et al. Distal tibia fractures: management and complications of 101 cases. Int Orthop 2010;34(4):583-588. DOI: 10.1007/s00264-009-0832-z.

6. Ali AM, Burton $M$, Hashmi $M$, et al. Outcome of complex fractures of the tibial plateau treated with a beam-loading ring fixation system. J Bone Joint Surg Br 2003;85(5):691-699. DOI: 10.1302/0301620X.85B5.13855.

7. Blokker $\mathrm{CP}$, Rorabeck $\mathrm{CH}$, Bourne RB. Tibial plateau fractures. An analysis of the results of treatment in 60 patients. Clin Orthop Relat Res 1984(182):193-199. DOI: 10.1097/00003086-19840100000025.

8. Ramos T, Ekholm C, Eriksson BI, et al. The llizarov external fixator-a useful alternative for the treatment of proximal tibial fractures. A prospective observational study of 30 consecutive patients. BMC Musculoskelet Disord 2013;14(1):11. DOI: 10.1186/1471-2474-14-11.

9. Manidakis N, Dosani A, Dimitriou R, et al. Tibial plateau fractures: functional outcome and incidence of osteoarthritis in 125 cases. Int Orthop 2010;34(4):565-570. DOI: 10.1007/s00264-009-0790-5.

10. Lee JA, Papadakis SA, Moon C, et al. Tibial plateau fractures treated with the less invasive stabilisation system. Int Orthop 2007;31(3): 415-418. DOI: 10.1007/s00264-006-0176-x.

11. Ahearn N, Oppy A, Halliday R, et al. The outcome following fixation of bicondylar tibial plateau fractures. Bone Joint J 2014;96-B(7): 956-962. DOI: 10.1302/0301-620X.96B7.32837.

12. Jansen $H$, Frey $S P$, Doht $S$, et al. Medium-term results after complex intra-articular fractures of the tibial plateau. J Orthop Sci 2013;18(4):569-577. DOI: 10.1007/s00776-013-0404-3.

13. Ali AM. Outcomes of open bicondylar tibial plateau fractures treated with llizarov external fixator with or without minimal internal fixation. Eur J Orthop Surg Traumatol 2013;23(3):349-355. DOI: 10.1007/ s00590-012-0989-9.

14. Canadian Orthopaedic Trauma Society. Open reduction and internal fixation compared with circular fixator application for bicondylar tibial plateau fractures. Results of a multicenter, prospective, randomized clinical trial. J Bone Joint Surg Am 2006;88(12):2613-2623. DOI: 10.2106/00004623-200612000-00008.

15. Warschawski Y, Elbaz A, Segal G, et al. Gait characteristics and quality of life perception of patients following tibial plateau fracture. Arch Orthop Trauma Surg 2015;135(11):1541-1546. DOI: 10.1007/s00402015-2325-4.

16. Elsoe R, Larsen P, Petruskevicius J, et al. Complex tibial fractures are associated with lower social classes and predict early exit from employment and worse patient-reported QOL: a prospective observational study of 46 complex tibial fractures treated with a ring fixator. Strateg Trauma Limb Reconstr 2018;13(1):25-33. DOI: 10.1007/ s11751-017-0301-y.

17. Elsoe R, Larsen P. Asymmetry in gait pattern following bicondylar tibial plateau fractures-A prospective one-year cohort study. Injury 2017;48(7):1657-1661. DOI: 10.1016/j.injury.2017.04.045.

18. Pun TB, Krishnamoorthy VP, Poonnoose PM, et al. Outcome of schatzker type V and VI tibial plateau fractures. Indian J Orthop 2014;48(1):35. DOI: 10.4103/0019-5413.125490.

19. Lansinger $O$, Bergman $B$, Korner $L$, et al. Tibial condylar fractures. $A$ twenty-year follow-up. J Bone Joint Surgery Am 1986;68(1):13-19. DOI: 10.2106/00004623-198668010-00003.

20. Stevens DG, Beharry R, McKee MD, et al. The long-term functional outcome of operatively treated tibial plateau fractures. J Orthop Trauma 2001;15(5):312-320. DOI: 10.1097/00005131-20010600000002.

21. Honkonen SE. Degenerative arthritis after tibial plateau fractures. J Orthop 1995;9(4):273-277. DOI: 10.1097/00005131-19950904000001.

22. Wasserstein D, Henry P, Paterson JM, et al. Risk of total knee arthroplasty after operatively treated tibial plateau fracture: a matched-population-based cohort study. J Bone Joint Surg Am 2014;96(2):144-150. DOI: 10.2106/JBJS.L.01691.

23. Scott CEH, Davidson E, MacDonald DJ, et al. Total knee arthroplasty following tibial plateau fracture: a matched cohort study. Bone Joint J 2015;97-B(4):532-538. DOI: 10.1302/0301-620X.97B4.34789.

24. Marsh JL, Slongo TF, Slongo J, et al. Fracture and dislocation classification compendium - 2007: orthopadic trauma assocoation classification, database and outcome committee. J Orthop Trauma 2007;21(Supp. 10):1-133. DOI: 10.1097/00005131-200711101-00001. 
25. von Elm E, Altman DG, Egger $M$, et al. The strengthening the reporting of observational studies in epidemiology (STROBE) statement: guidelines for reporting observational studies. Int J Surg 2014;12(12):1495-1499. DOI: 10.1016/j.ijsu.2014.07. 013.

26. KOOS questionnary [KOOS web site]. Available at: http:/www.koos. nu. Accessed June 12, 2011.

27. Paradowski PT, Bergman S, Sunden-Lundius A, et al. Knee complaints vary with age and gender in the adult population. Population-based reference data for the knee injury and osteoarthritis outcome score (KOOS). BMC Musculoskelet Disord 2006;7(1):38. DOI: 10.1186/14712474-7-38.

28. Eq5D Questionnary http://www.euroqol.org/about-eq-5d/ publications/user-guide.html. Accessed June 122012.

29. Rabin R, de Charro F. EQ-5D: a measure of health status from the euroqol group. Ann Med, Erasmus University Rotterdam, Centre for Health Policy and Law; The Netherlands 2001;33(5):337-343. DOI: 10.3109/07853890109002087.

30. Sørensen J, Davidsen M, Gudex C, et al. Danish EQ-5D population norms. Scand J Public Health 2009;37(5):467-474. DOI: 10.1177/1403494809105286.

31. Kellgren JH, Lawrence JS. Radiological assessment of osteoarthrosis. Ann Rheum Dis 1957;16(4):494-502. DOI: 10.1136/ard.16.4. 494.

32. Parmar V, Shyam Kumar AJ, Harper WM. Reliability of the GAITRite walkway system for the quantification of temporo-spatial parameters of gait in young and older people. Gait Posture 2006;23(4):523. DOI: 10.1016/j.gaitpost.2005.06.001author reply 524-5.

33. Yogev G, Plotnik M, Peretz C, et al. Gait asymmetry in patients with Parkinson's disease and elderly fallers: when does the bilateral coordination of gait require attention? Exp Brain Res 2007;177(3) 336-346. DOI: 10.1007/s00221-006-0676-3.

34. Oberg T, Karsznia A, Oberg K. Basic gait parameters: Reference data for normal subjects, 10-79 years of age. J Rehabil Res Dev 1993;30(2):210-223.

35. Patterson KK, Gage WH, Brooks D, et al. Evaluation of gait symmetry after stroke: a comparison of current methods and recommendations for standardization. Gait Posture 2010;31(2):241-246. DOI: 10.1016/ j.gaitpost.2009.10.014.

36. Roos EM, Engelhart L, Ranstam J, et al. ICRS recommendation document: Patient-reported outcome instruments for use in patients with articular cartilage defects. Cartilage 2011;2(2):122-136. DOI: 10.1177/1947603510391084.

37. Keightley AJ, Nawaz SZ, Jacob JT, et al. Ilizarov management of schatzker IV to VI fractures of the tibial plateau: 105 fractures at a mean follow-up of 7.8 years. Bone Joint J 2015;97-B(12):1693-1697. DOI: 10.1302/0301-620X.97B12.34635.

38. Volpin G, Dowd GS, Stein H, et al. Degenerative arthritis after intraarticular fractures of the knee. Long-term results. J Bone Joint Surg Br 1990;72(4):634-638. DOI: 10.1302/0301-620X.72B4.2380219.

39. Marsh JL, Buckwalter J, Gelberman R, et al. Articular fractures: does an anatomic reduction really change the result? J Bone Joint Surg Am 2002;84-A(7):1259-1271. DOI: 10.2106/00004623-20020700000026.

40. Honkonen SE, Kannus P, Natri A, et al. Isokinetic performance of the thigh muscles after tibial plateau fractures. Int Orthop 1997;21(5):323326. DOI: $10.1007 / \mathrm{s} 002640050177$.

41. Gaston P, Will EM, Keating JF. Recovery of knee function following fracture of the tibial plateau. J Bone Joint Surg Br 2005;87(9): 1233-1236. DOI: 10.1302/0301-620X.87B9.16276. 